\title{
Economic evaluations in water-fluoridation: a scoping review
}

Rodrigo Mariño ${ }^{1}$ and Carlos Zaror $2,3^{*}$

\begin{abstract}
Background: Community water fluoridation (CWF) is considered one of the 10 greatest public health achievements of the twentieth century and has been a cornerstone strategies for the prevention and control of dental caries in many countries. However, for decision-makers the effectiveness and safety of any given intervention is not always sufficient to decide on the best option. Economic evaluations (EE) provide key information that managers weigh, alongside other evidence. This study reviews the relevant literature on EE in CWF.

Methods: A systematic database search up to August 2019 was carried out using MEDLINE, EMBASE, Cochrane Library, LILACS, Paediatric Economic Database Evaluation and National Health Service Economic Evaluation Database. The review included full economic evaluations on CWF programs, written in English, Spanish or Portuguese. The selection process and data extraction were carried out by two researchers independently. A qualitative synthesis of the results was performed.
\end{abstract}

Results: Of 498 identified articles, 24 studies met the inclusion criteria; 11 corresponded to cost-benefit analysis; nine were cost-effectiveness analyses; and four cost-utility studies. Two cost-utility studies used Disability-Adjusted Life Years" one used Quality-Adjusted Tooth Years, and another Quality-Adjusted Life Years. EEs were conducted in eight countries. All studies concluded that water fluoridation was a cost-effective strategy when it was compared with non-fluoridated communities, independently of the perspective, time horizon or discount rate applied. Four studies adopted a lifetime time horizon. The outcome measures included caries averted $(n=14)$ and savings cost of dental treatment $(n=4)$. Most of the studies reported a caries reduction effects between 25 and $40 \%$.

Conclusion: Findings indicated that CWF represents an appropriate use of communities' resources, using a range of economic evaluation methods and in different locations. These findings provide evidence to decision-makers which they could use as an aid to deciding on resource allocation.

Keywords: Fluoridation, Cost-benefit analysis, Health economics, Oral health

\section{Introduction}

Dental caries is the most prevalent chronic disease in the world today, and affecting a significant proportion of the world's population [1]. In permanent dentition, dental caries is the most prevalent condition, affecting 34.1\%

\footnotetext{
* Correspondence: carlos.zaror@ufrontera.cl

${ }^{2}$ Department of Pediatric Dentistry and Orthodontics; Faculty of Dentistry, Universidad de La Frontera, Manuel Montt \#112, Temuco, Chile

${ }^{3}$ Center for Research in Epidemiology, Economics and Oral Public Health (CIEESPO), Faculty of Dentistry, Universidad de La Frontera, Temuco, Chile Full list of author information is available at the end of the article
}

of the world's population ( 2.5 billion people) according to the global morbidity burden study of 2015 [1]. In primary dentition, dental caries is the 10th most prevalent condition, affecting $7.8 \%$ of the population, that is, 573 million children worldwide [1]. The health consequences of dental caries are serious and this disease can also greatly affect the quality of life of those who suffer from it [2].

While factors including the consumption of refined carbohydrates were responsible for the rise of caries in the first half of the last century, exposure to fluoride has

(c) The Author(s). 2020 Open Access This article is licensed under a Creative Commons Attribution 4.0 International License which permits use, sharing, adaptation, distribution and reproduction in any medium or format, as long as you give appropriate credit to the original author(s) and the source, provide a link to the Creative Commons licence, and indicate if changes were made. The images or other third party material in this article are included in the article's Creative Commons licence, unless indicated otherwise in a credit line to the material. If material is not included in the article's Creative Commons licence and your intended use is not permitted by statutory regulation or exceeds the permitted use, you will need to obtain permission directly from the copyright holder. To view a copy of this licence, visit http://creativecommons.org/licenses/by/4.0/ The Creative Commons Public Domain Dedication waiver (http://creativecommons.org/publicdomain/zero/1.0/) applies to the data made available in this article, unless otherwise stated in a credit line to the data. 
had a crucial role in improving oral health during the past few decades [3]. Fluoride is the leading strategy in the noninvasive management of dental caries, and it has been incorporated as a public health measure to reduce the prevalence of that disease [4]. Fluoride's main mechanism is topical, stimulating the remineralization of early carious lesions and reducing the risk of demineralizing healthy enamel [4]. Fluoride is now accepted as a safe, effective, efficient and appropriate mechanism for the prevention of dental caries [5]. Indeed, the use of fluorides is recognized as one of the most successful measures for the prevention of disease in the history of public health [6]. Fluoride can be delivered to individuals as a dental preventive measure through a variety of mechanisms. It can be administered systemically through water, milk, or salt or topically available as toothpastes and other dental products such as varnishes, gels and mouthwashes [5].

In the mid-1940s, fluoride was first adjusted to community water fluoridation (CWF), it has since then been introduced to the public drinking water in 26 countries around the world. The adjustment of fluoride content to optimal levels $(0.6-1.0 \mathrm{ppm}$ or $0.6-1 \mathrm{mg} / \mathrm{L})$ in community water is the basis of prevention and control strategies for dental caries in those countries [5]. Currently, fluoride adjusted CWF benefits 372 million people. In addition, another 57 million people in 27 countries receive this benefit from water supplies that are naturally fluoridated [7]. The evidence indicates that a 26 to a $35 \%$ reduction in dental caries can be achieved with this public health measure in permanent and primary dentition, respectively [8].

The effectiveness and safety of any given intervention may not be enough to decide on its implementation. Other factors, including cost-effectiveness, as well as the political, organizational, social, ethical and legal impacts must be considered, especially when applied within the public health context [9]. Health service managers, programmers and planners are required to select the interventions with the highest impact, however these interventions come at a cost so planners need to assess the relative efficiency of interventions. Economic evaluations (EE) describe the relative effectiveness of interventions in comparison to the relative costs, this approach enables planners to identify those interventions that can maximize health for a given budget. It is now well established and recognized that EE is a central component of the objective evaluation of new technology/therapies and preventive programs that seek to replace current treatments or practices [10].

An economic evaluation is defined as "the comparative analysis of alternative actions in terms of their costs and their consequences in order to assist in policy decision" [11]. There are several important components to this definition, the first is that an economic evaluation must compare alternative interventions. Secondly, an economic evaluation measures not only costs, but also results or consequences. Thirdly, the technique represents only one dimension within a broader, integrated and cyclical decision-making and evaluation process [11]. Table 1 summarizes the economic evaluation process. Full details of economic evaluation methods, as applied to healthcare, can be found elsewhere [11].

In the context of diminishing public resources for oral health care and increasingly sophisticated treatment options, decision-makers may not have enough information to identify the financial benefit per monetary unit of resources required for most health interventions. The need to understand health and healthcare systems and how to best allocate scarce resources, requires decision-makers to apply the full range of methods and skills to assure these resources are used wisely [13]. It is in this context that economic evaluations (EE) are relevant, as they provide information that managers weigh, alongside other evidence. Nonetheless, although, there are examples in the literature of EE in oral health, until recently, its overall use in oral health was limited. Recent reviews indicate that this is changing [14].

As the importance of economic evaluation in oral health will increase in the future, to make this process relevant to policy makers, this manuscript will review the relevant literature on EEs in CWF, describing their

Table 1 Steps for economic evaluation

Step 1. Define objective of the economic evaluation

Step 2. Define economic evaluation framework

- Perspective of the economic analysis

- Alternatives being compared

- Time horizon

Step 3. Determine costs and benefits of alternatives

- Define all activities

- Specify measurements

- Collect cost data

- Calculate costs

- Discount

- Define outcomes

- Select evaluation design

- Collect data

- Analyze data

Step 4. Relate costs to outcomes

- Ratio

Step 5. Adjust for uncertainties

- Sensitivity analysis

Step 6. Summarize, Interpret, and report findings Modified from: Splett [12] 
characteristics and reviewing their effectiveness and limitations.

\section{Methods}

\section{Sources of information and search strategy}

This scoping review was reported according to the Preferred Reporting Items for Systematic reviews and MetaAnalyses extension for Scoping Reviews (PRISMA-ScR) guidelines [15]. A systematic search of the literature published up to August 15, 2019, was conducted to identify existing economic evaluations of waterfluoridation. The following databases were used: MEDLINE (via PubMed), EMBASE, Cochrane Library, LILACS, Paediatric Economic Database Evaluation (PEDE), National Health Service Economic Evaluation Database (NHS EED). Because some economic evaluations about water fluoridation are not published in the academic literature, reference listings of retrieved articles and previous systematic reviews were hand searched to identify other possible studies. The details of the search strategy are given in an additional file.

\section{Study selection}

Full EEs comparing both the costs and consequences of water fluoridation with status-quo or other interventions [11], in English, Spanish and Portuguese were included. Excluded were discussion papers, reviews and study protocols and incomplete economic evaluation, that is those where only the costs or consequences of water fluoridation were examined.

All references identified were extracted to an EndNote X9 database to facilitate their management and duplicate articles were eliminated. Articles were selected by title and abstract, and then by full text according to the eligibility criteria, using Rayyan online software (https://rayyan.qcri.org), with two researchers (RM and $\mathrm{CZ}$ ) working independently. If there was a discrepancy, a consensus was reached. The reviewers were not blinded to the authors or journals. The reasons for exclusions were recorded.

\section{Data extraction}

Two reviewers independently extracted data from each article that met the inclusion criteria, through a standardized spreadsheet. No quantitative analyses were performed beyond descriptive statistics to summarize findings. Rather a qualitative synthesis was performed. Extracted information included: author, year, country, type of economic evaluation, perspective, source of effectiveness outcome measure, outcome measure, time horizon, discount rate, price year, currency unit and main results.

Eligible studies were critically appraised by two independent reviewers (CZ and $\mathrm{RM}$ ) at the study level for methodological quality using the Joanna Briggs Institute (JBI) Checklist for Economic Evaluations [16]. The level of methodological quality was determined as follows: fair quality $=$ less than $40 \%$ of the items presented; moderate quality = between 41 and $80 \%$ of the items presented; good quality $=$ more than $80 \%$ of the items presented [17]. Discrepancies during the data extraction process and critical appraisal were identified and resolved through consensus.

\section{Results}

A total of 498 articles were found during the database searches. Of these, 108 were duplicates and were eliminated, leaving 390 articles for review. After title and abstract review, 356 articles were excluded. Thirty-four articles were selected for full text review. Of these, five were excluded due to being cost studies [18-22]; two due to being review articles [23, 24]; two did not have comparators $[25,26]$ and two articles were in French [27, 28]. In addition, three articles were identified by hand search and other online sources. Finally, 26 articles corresponding to 24 studies [29-52] were included, because 2 studies were reported in more than one article $[53,54]$. Figure 1 shows the selection process followed.

The main characteristics of the included studies are presented in Table 2 (ordered by year of publication). The studies included were published between 1973 and 2017. By year of publication, by 10-year categories, there is a trend towards a gradual increase in the number of publications; in particular, between 2010 and $2017(n=$ 11). Eleven studies were cost-benefit analyses; nine were cost-effectiveness analyses; and four were cost-utility studies. Studies were conducted in eight countries: Australia $(n=6)$; USA $(n=6)$; New Zealand $(n=4)$; United Kingdom $(n=2)$; Chile $(n=2)$; Spain $(n=2)$; South Africa $(n=1)$ and Canada $(n=1)$ (See Table 2). Few studies reported the prevalence of caries in the intervening communities, (35 to $96 \%$ ).

The most commonly used perspective was the payor's $(n=12)$ while eleven studies used the societal one. The perspective is the point of view from which the economic evaluation is carried out and this determines what costs and benefits should be included in the analysis. The payer's perspective includes only the costs that are directly related to the production of the health service or program whereas the societal perspective also includes the costs incurred by the patient and his/her family, either to access the service or other expenses that can be assumed as a result of the intervention or due to the loss of the productivity [11].

The main comparator was communities without CWF. Only two studies compared the cost-effectiveness of CWF with other preventive measures such as dental sealants, fluoride varnish and, tooth brushing with 


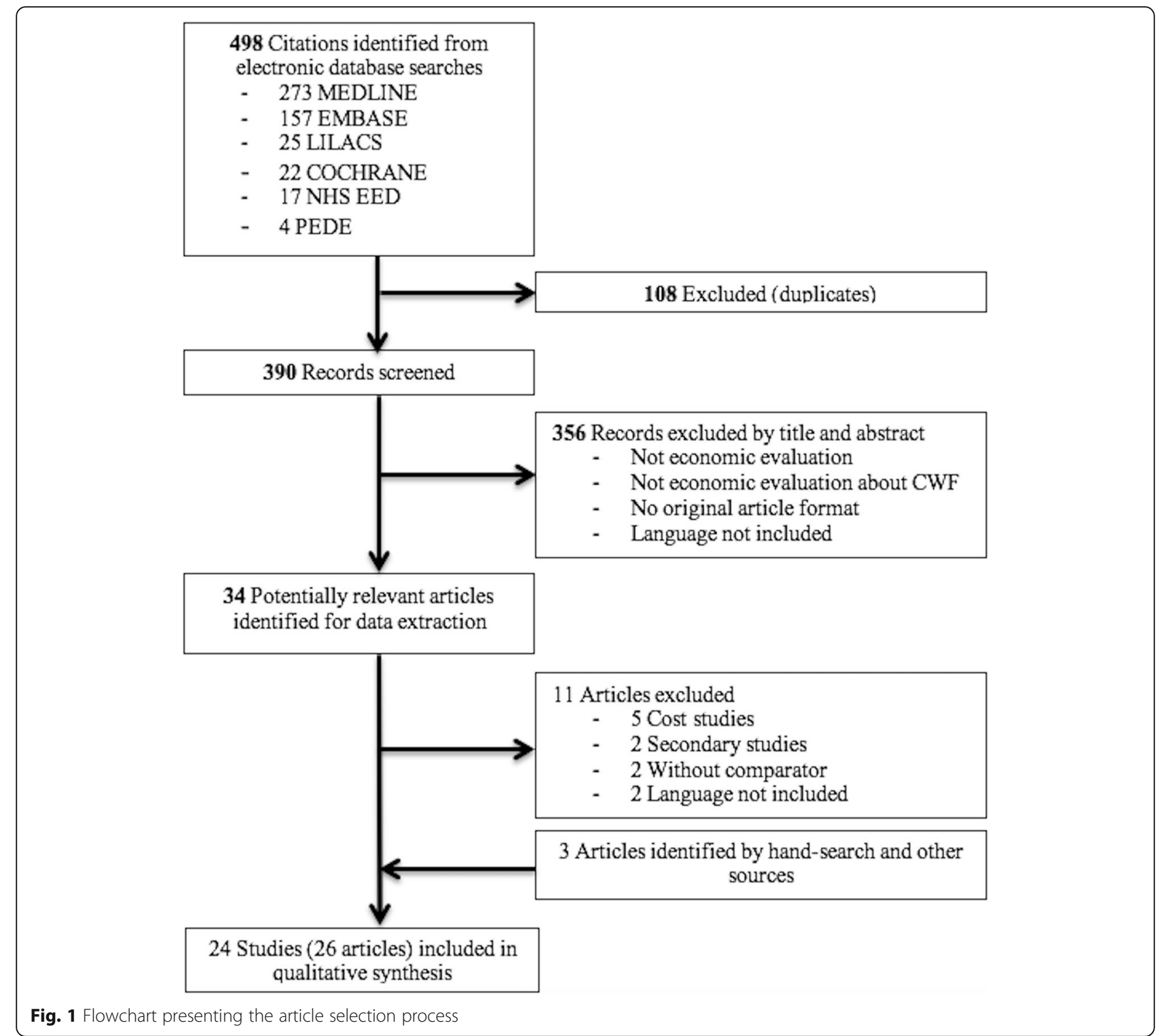

fluoride toothpaste [52, 54]. With one exception, most of the studies considered a general population older than 5 years of age. The exception was Edelstein and collaborators who included preschoolers [51]. Most of the studies $(n=15)$ adopted time horizons of 15 years or more. However, four studies [30, 43, 44] adopted a lifetime time horizon Regarding the source of data and modelling, most studies $(n=21)$ built Markov models with literature data from observational studies and only one study analyzed data from a cohort study. No studies reported a decision analysis model. (See Table 2). A model is a simple representation of a reality and allows extrapolating of cost and effectiveness parameters beyond the data observed in a clinical trial. It also allows extrapolating of results obtained in one clinical setting in to the general population [55].
Regarding costs and outcomes, all studies incorporated the intervention costs, composed of a onetime investment cost and amortized to obtain annual value; the recurrent fixed costs (costs of maintenance, operation and monitoring); and a variable recurrent cost (chemical and supplies cost) [45]. Additionally, studies from a social perspective included costs for lost productivity due to the time spent in dental care and transportation costs to and from the health center.

Most of the studies reported a caries reduction effects between 25 and $40 \%$. The outcomes most frequently measured were caries averted $(n=14)$ and cost saving of dental treatment $(n=4)$. Cost-utility studies used Disability-Adjusted Life Year (DALY) in two studies, Quality-Adjusted Tooth Years 


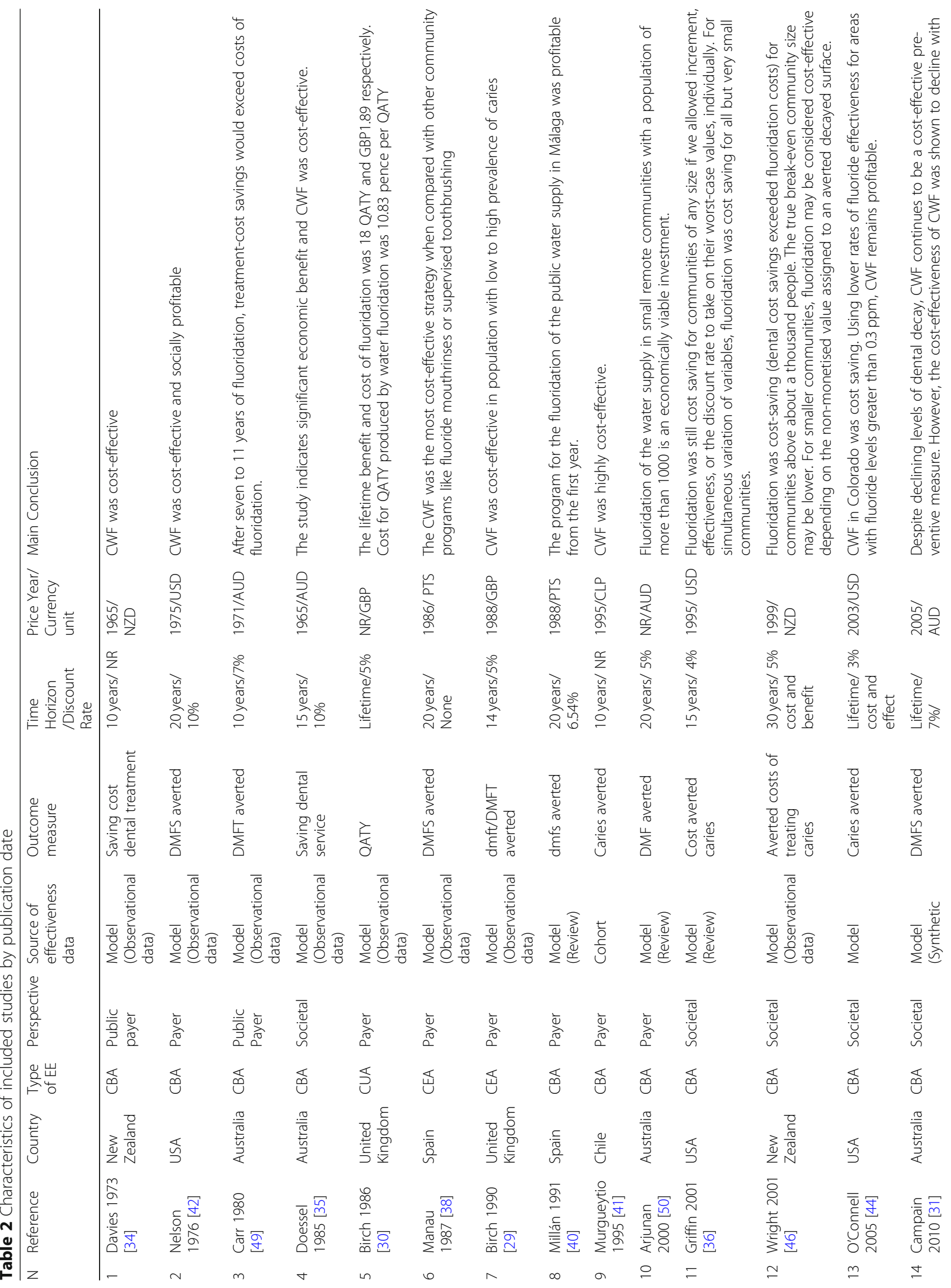




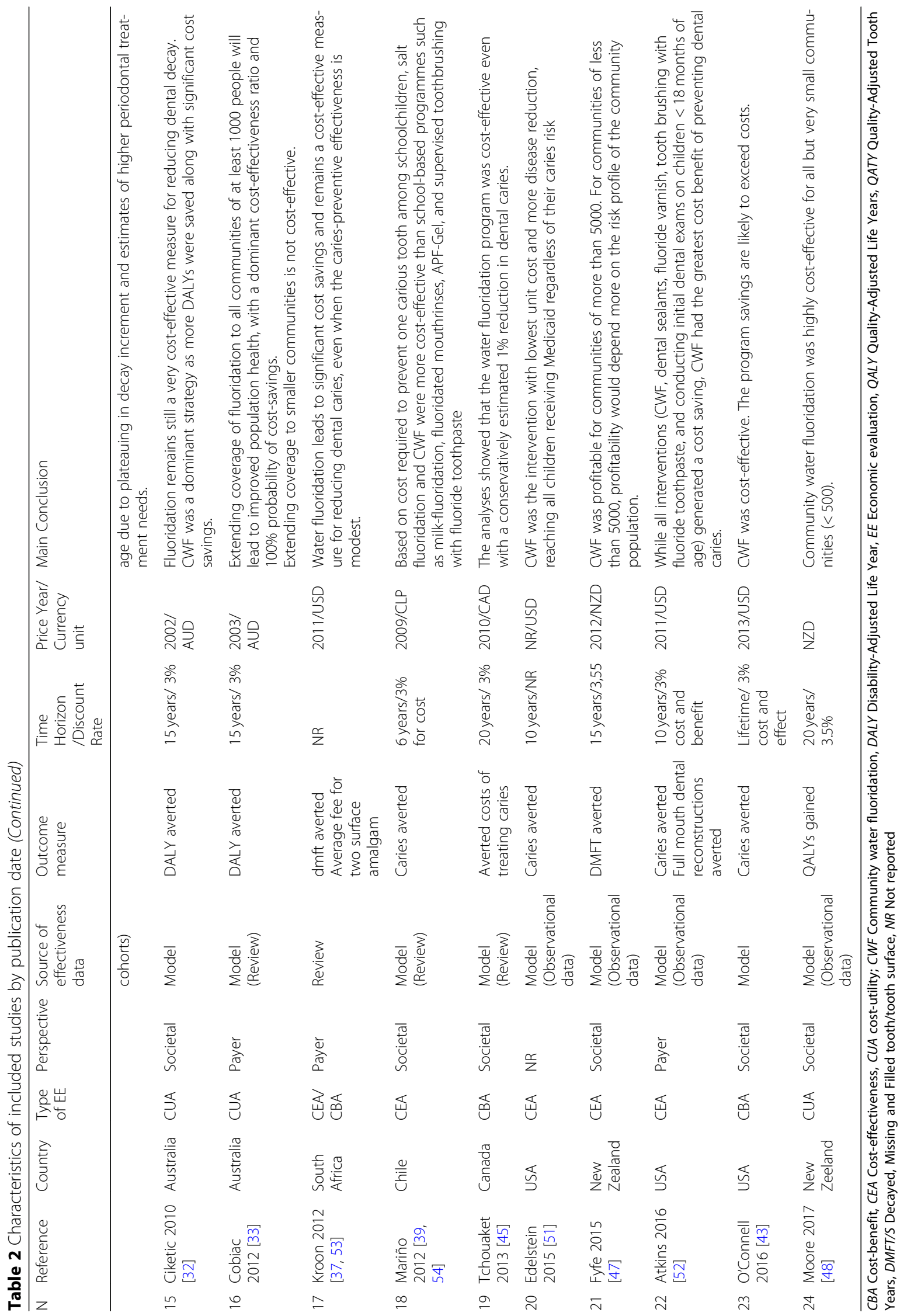


(QATY) in one study, and Quality-Adjusted Life Years (QALY) in another (See Table 2).

All studies supported the use of CWF as a cost-saving strategy when it was compared with a non-fluoridated community, independent of the perspective, time horizon and discount rate applied. Studies also showed that water fluoridation was cost-effective even when the estimated reduction of prevalence was lower than 25\% [33, 37, 45]. Moreover, evidence of communities with different concentrations of fluoride in their water supply, found that this measure proved to be cost-effective even in communities with fluoride levels of slightly more than $0.3 \mathrm{ppm}$ [44]. However, two studies showed that in small communities (population of less than 1000 population) the water fluoridation did not achieve cost saving [36, 50]. Additionally, Campain and her collaborators [39], using a time-age model, factored the impact of dental and periodontal treatment needs on the cost savings from community water-fluoridation. They suggested that consideration needed to be given to preventive strategies that contained costs of treatment needs arising out of greater tooth retention in an ageing population (e.g., treatment of periodontal disease). Only one study assessed the cost-effectiveness in preschool populations with different caries risk, and concluded that CWF produced cost savings regardless of caries risk [51].

Most of the studies included showed a moderate methodological quality $(12 / 24)$ and eight studies met at least $80 \%$ of the criteria in the JBI Checklist for Economic Evaluations and were considered high quality (Table 3). All of the studies with fair quality were published before 2000, with the exception of the study by Edelstein and collaborators, published in 2015. The main methodological shortcoming observed was that studies did not provide either a comprehensive description of the alternatives (9/24), did not measure costs and outcomes accurately, or that the sources of information used were unreliable (10/24). Although most of the studies reported a cost-effectiveness ratio for WF, few reported the incremental cost-effectiveness ratio (ICER) (19/24). The ICER informs how much more we must pay to obtain an additional effectiveness unit of the new intervention in relation to its comparator [11]. Furthermore, fifteen studies conducted a sensitivity analysis to investigate uncertainty in estimates of costs or outcomes. Finally, only 10 studies described the study setting adequately and discussed the issues of transferability of findings and how the results were generalizable to other settings with similar characteristics.

\section{Discussion}

A scoping review of studies concerning EE of CWF for dental caries prevention, published after 1973, revealed 24 EEs of CWF. Most of the studies identified were either cost effectiveness or cost benefit analyses. The majority of studies, even when they reported cost per carious lesion averted, presented final analyses in terms of monetary costs and benefits. Overall, findings indicated that there were significant economic benefits to using CWF, representing an efficient use of financial resources. Notably, this general conclusion remains when using different methods of evaluation or different settings.

Nonetheless, few studies addressed variables such as the size of the community, the declining dental caries incidence and greater tooth retention; or the ageing of the population. These factors would impact on the expected benefits and costs when modelling future outcomes. Griffin and her collaborators' [36] also addressed the question of whether, in the face of declining dental caries incidence, CWF is still economically and socially justifiable CWF. Regarding the extent to which net economic benefits exist in small communities, studies indicated a population of 1000 population as the cut-off point for cost-effectiveness [33, 50]. Moore and collaborators., meanwhile, showed that CWF was highly costeffective for all but very small communities $(<500)$ [48]. The main justification provided for these studies was that the cost of its implementation and maintenance is greater than the averted costs, despite the higher rates of caries in more regional and remote populations. These results should be considered with caution, since the studies included, did not always consider the costs of complex treatments (root canal treatment, implants, crowns, etc.), assuming that the costs of treating adverse effects were negligible, or that the effectiveness was the same regardless of age. However, two studies questioned that conclusion and indicated that CWF in communities of any size would be cost saving $[36,46]$.

As mentioned, most of the included studies considered that the adverse effects of CWF, such as dental fluorosis, were negligible, and failed to include the costs associated with the treatment of these conditions. Although, the problems caused in the less severe forms of fluorosis are even considered to be aesthetically pleasing [56], the evidence shows that fluorosis causes aesthetic problems to up to $40 \%$ of those surveyed, when considering fluorosis of any level [8]. The treatment of fluorosis ranges from bleaching, in the case of mild fluorosis, to complex treatments such as veneers and crowns in the case of moderate or severe fluorosis [57]. When the time horizon of a lifetime is used, the costs associated with the treatment and retreatment of dental fluorosis can be significant and should therefore be included.

Furthermore, it must be noted that programs and interventions in health might be cost-inefficient, but 


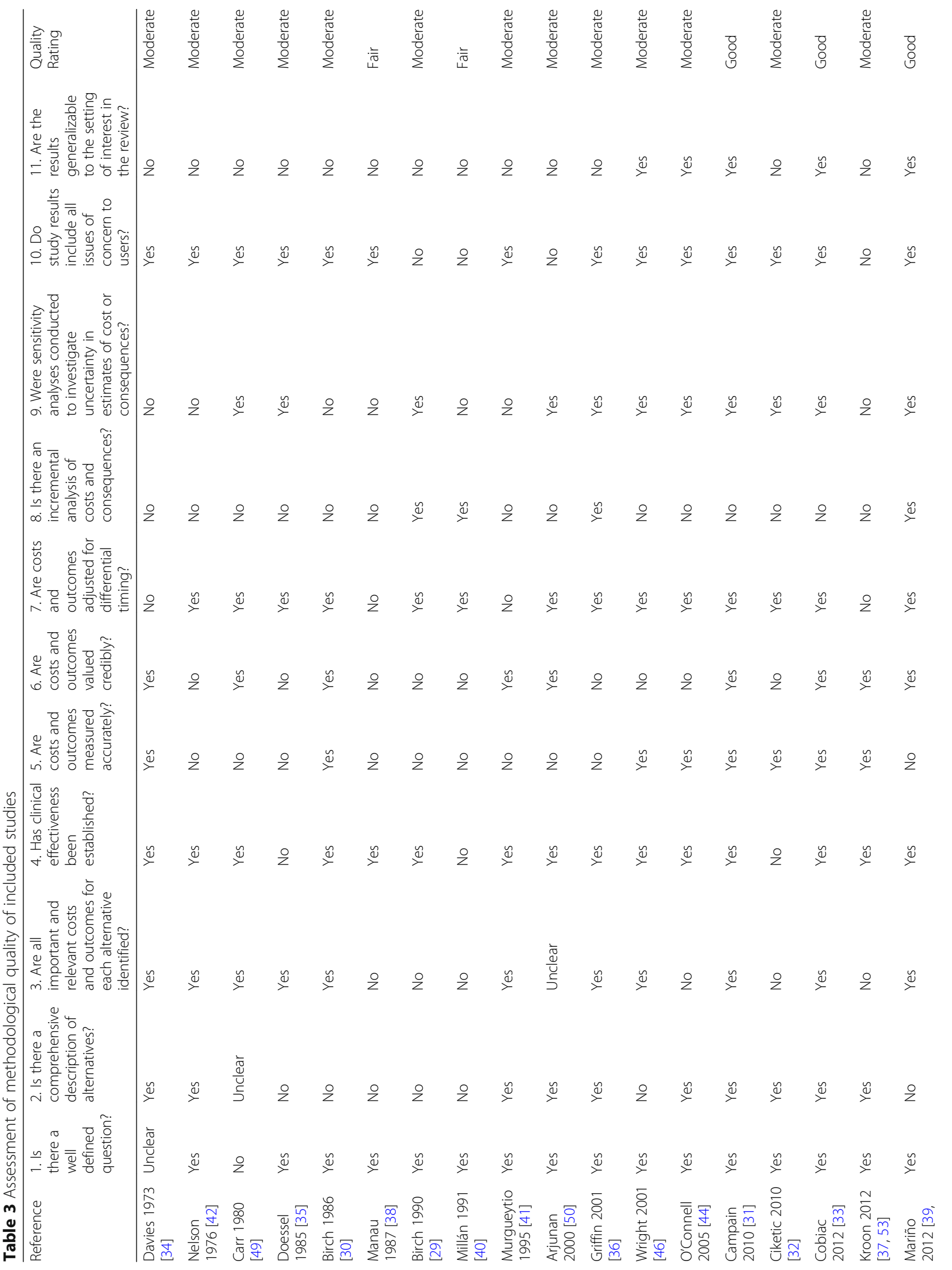




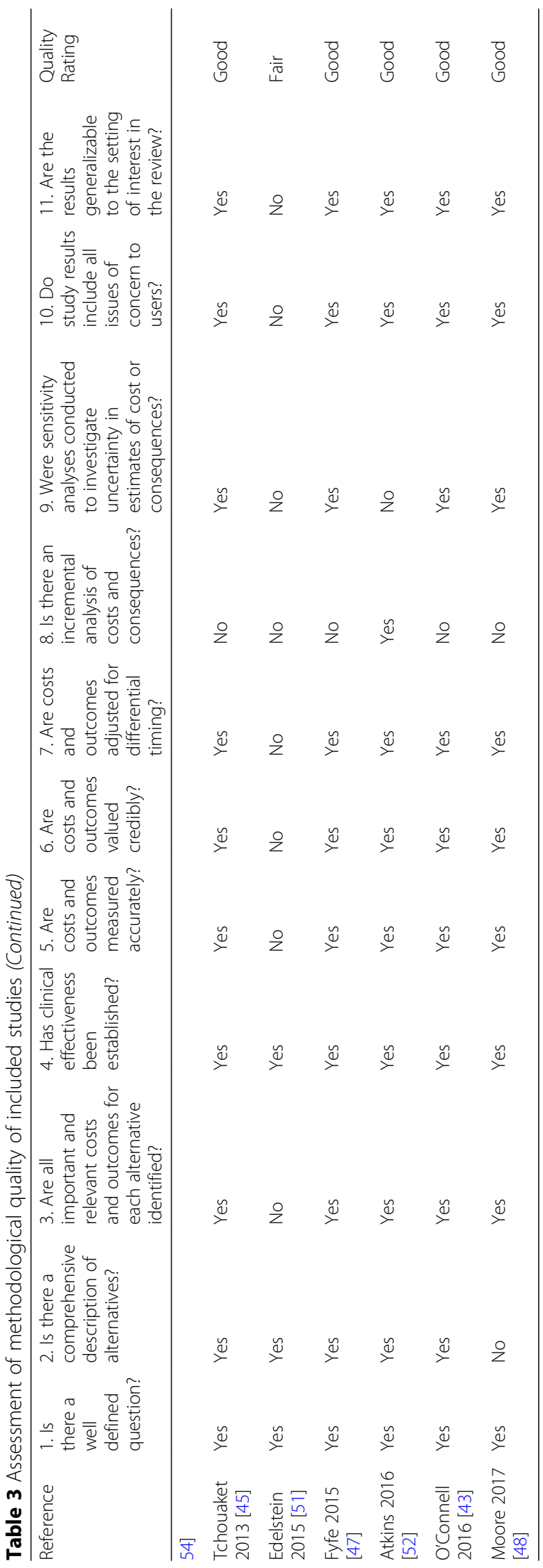


could be used regardless because of ethical or cultural considerations. For example, life-saving interventions, or those that improve quality of life.

Campain and collaborators [39] took into consideration the effects of an ageing population, lower rates of edentulism, and consequently higher rates of treatment need for the gums and supporting tissues of the teeth. They found that CWF continued to be a cost-effective preventive measure. However, the study suggested that CWF might stop being cost-effective due to the additional costs of treatment of periodontal disease and replacement/retreatment of old restorations, etc., highlighting the need to incorporate preventive measures in oral health.

Only four cost-utility studies were identified. CUA was developed to help decision-makers compare the value of alternative interventions that have different health outcomes. In those cases, CUA facilitates these comparisons without the need to place monetary value on different health states, being more useful when alternative treatment strategies produce different types of outcomes [58]. Since CUA reflects the preference that the patient's preference has regarding a state of health, information related to the patient is lost at the time of making decisions. When using another outcome measure. For example, patients can choose a tooth-colored composite resin instead of an amalgam for restoration, despite the costs involved. The absence of CUA may be due to the absence of suitable instruments to measure utility in oral health [59]. On the other hand, evidence shows that CUAs tend to be less favorable than CEAs in short time horizons, which may discourage their use [60].

Studies included in this review were conducted in eight countries, with half of the studies based either in Australia or in the USA. EE are very context specific, and most likely reflect the local conditions from those countries only [61]. Thus, care must be exerted when generalizing results to another jurisdiction, as it remains difficult to compare economic results from one country to another [61] or even within a jurisdiction from a given year to another, and the cost of a technology may also vary after its initial introduction [62]. There are many reasons for the difficulty of comparing costs, among them: differences in price of resources; variability in willingness to pay for health and health care; variations in prices of health consequences; variation in approaches to treatment and resource use [63]. Furthermore, the risk behaviors of the population, health care infrastructure, and a society's ideological and ethical norms could also differ [64].

Therefore, the methodological quality of the existing EEs plays a fundamental role when transferring an economic evaluation to another context [65] and those who conduct EE should pay attention to methodological issues. In the present review, most studies used modelling to asses cost, benefits and effectiveness. A crucial feature of models is their transparency and reproducibility in order to allow adaptation to different scenarios [55]. The effectiveness of any intervention must be based on the best available data and clearly stated. Therefore, policy makers should be able to identify if the model reflects the usual practice and whether they used an adequate comparator. They must also identify whether the information on which the model is based is the best quality available according to the technology evaluated, population studied and study perspective. A number of the EE included in this review failed some of these aspects.

Differences in caries rates between fluoridated and non-fluoridated communities reported by the included studies are in the order of $30 \%$. Although other preventive strategies such as fluoride varnishes, dental sealants or brushing with fluoride toothpaste can be more effective and also costs saving, drinking water has the advantage of reaching people of all ages, and education and income levels within a community [66]. Manau and collaborators showed that CWF was the most cost-effective strategy when compared with other community programs such as fluoride mouthrinses or supervised toothbrushing [38]. This is reinforced by Mariño and his collaborators [54] who found that CWF was more costeffective than school-based programmes such as milkfluoridation, fluoridated mouthrinses or APF-Gel.

The time period of an analysis is usually short and not related to the lifespan of the population. Because of the nature of analyses required to inform fluoridation decisions, prospective epidemiological data for a lifetime, or at least from early childhood to advanced old age, are needed. Only four studies [30, 43, 44] used a time horizon of lifetime, although the methodological guidelines for the preparation of EE recommend a lifetime horizon for chronic diseases such as tooth decay [67].

Although we were systematic in our review, it is possible that we may have missed publications. However, we believe that this was minimized due to the sensitive search strategy used, the additional search of references by hand and the double independent review process used. Additionally, it was not possible in this review to conduct a full validation of each model.

\section{Conclusion}

A scoping review was conducted to provide a review of the evidence concerning EE of CWF for dental caries prevention. Findings indicated that CWF represents an appropriate use of communities' resources, using a range of economic evaluation methods and in different locations. In accordance with the evidence found, future EEs of CWF should include a broad perspective that covers a 
lifetime temporal horizon and includes not only the direct cost of investment and operation, but also other negative and positive intangible costs of water fluoridation, such as, political cost (e.g., cost promotion of CWF) and adverse effect cost (e.g., treatment of fluorosis, which might include complex rehabilitation), among others. In addition, future studies should consider the decline in caries rates over time. Furthermore, the outcome measure should also consider changes in quality of life, subsequent to changes in oral health status.

Additionally, in view of changing technology, disease prevalence and socio demographic profile of the population, evaluation and research on the cost-effectiveness of CWF should be ongoing and locally based. Significantly, there are not conclusive results in communities less than 1000 , or in temporal horizons lower than 10 years. Finally, to facilitate the interpretation of the results by decision makers in health, the results should be summarized through the incremental cost-effectiveness ratio (ICER).

\section{Supplementary information}

Supplementary information accompanies this paper at https://doi.org/10. 1186/s12903-020-01100-y.

\section{Additional file 1. Search strategy used in each database.}

\section{Abbreviations \\ CBA: Cost-benefit; CEA: Cost-effectiveness; CUA: cost-utility; CWF: Community water fluoridation; DALY: Disability-Adjusted Life Year; EE: Economic evaluation; QALY: Quality-Adjusted Life Years; QATY: Quality-Adjusted Tooth Years}

\section{Acknowledgements}

Not applicable.

\section{Authors' contributions}

All authors have actively participated in the study and have made a substantial contribution to (1) either conception and design, or acquisition of data, or analysis and interpretation of data; as well as (2) the drafting of the article or its critical revision for important intellectual content; and (3) to the final approval of the version to be published. Each author believes that the manuscript represents honest work.

\section{Funding}

This project was partially funded by a grant from the Faculty of Dentistry, Universidad de La Frontera, Proyecto de Internacionalización para Investigación y Productividad 2019.

\section{Availability of data and materials}

The datasets used and/or analyzed during the current study are available from the corresponding author upon reasonable request.

\section{Ethics approval and consent to participate}

Formal ethical approval is not required as no primary data will be collected. As such, there are no patients involved, so the consent of the patient to participate is not required.

\section{Consent for publication}

Not applicable.

\section{Competing interests}

The authors declare that they have no competing interest. Rodrigo Mariño is a Section Editor for BMC Oral Health and Carlos Zaror is Associate Editor for BMC Oral Health.

\section{Author details}

'Melbourne Dental School, University of Melbourne, Melbourne, Australia. ${ }^{2}$ Department of Pediatric Dentistry and Orthodontics; Faculty of Dentistry, Universidad de La Frontera, Manuel Montt \#112, Temuco, Chile. ${ }^{3}$ Center for Research in Epidemiology, Economics and Oral Public Health (CIEESPO), Faculty of Dentistry, Universidad de La Frontera, Temuco, Chile.

Received: 1 October 2019 Accepted: 31 March 2020

Published online: 16 April 2020

\section{References}

1. Kassebaum NJ, Smith AGC, Bernabe E, Fleming TD, Reynolds AE, Vos T, et al. Global, regional, and National Prevalence, incidence, and disability-adjusted life years for Oral conditions for 195 countries, 1990-2015: a systematic analysis for the global burden of diseases, injuries, and risk factors. J Dent Res. 2017:96:380-7.

2. Matamala-Santander A, Rivera-Mendoza F, Zaror C. Impacto de la caries en la calidad de vida relacionada con la salud oral en Adolescentes: Revisión sistemática y meta-análisis. Int J Odontostomat. 2019;13:219-29.

3. Jones S, Burt BA, Petersen PE, Lennon MA. The effective use of fluorides in public health. Bull World Health Organ. 2005;83:670-6.

4. Cury JA, Tenuta LM. Enamel remineralization: controlling the caries disease or treating early caries lesions? Braz Oral Res. 2009;23(Suppl 1):23-30.

5. Centers for Disease Control and Prevention. Recommendations for using fluoride to prevent and control dental caries in the United States. MMWR Recomm Rep. 2001;50:1-42.

6. Centers for Disease Control and Prevention. Achievements in public health, 1900-1999: fluoridation of drinking water to prevent dental caries. JAMA. 2000;283:1283-6.

7. Aoun A, Darwiche F, Al Hayek S, Doumit J. The fluoride debate: the pros and cons of fluoridation. Prev Nutr Food Sci. 2018;23:171-80.

8. Iheozor-Ejiofor Z, Worthington HV, Walsh T, O'Malley L, Clarkson JE, Macey R, et al. Water fluoridation for the prevention of dental caries. Cochrane Database Syst Rev. 2015;(6):CD010856.

9. Vallejos C, Bustos L, de la Puente C, Reveco R, Velasquez M, Zaror C. The main methodological aspects in health technology assessment. Rev Med Chil. 2014;142(Suppl 1):S16-21.

10. Niessen LC, Douglass CW. Theoretical considerations in applying benefitcost and cost-effectiveness analyses to preventive dental programs. J Public Health Dent. 1984;44:156-68.

11. Drummond MF, Sculpher MJ, Torrance GW, O'Brien BJ, Stoddart GL. Methods for the economic evaluation of health care Programmes. 3rd ed. United Kingdom: Oxford University Press; 2005.

12. Splett $P$. The practitioner's guide to cost-effectiveness analysis of nutrition interventions. 1996. https://www.ncemch.org/NCEMCHpublications/ NtrnCstEff_Anl.pdf. Accessed 09 Apr 2020.

13. Glied S, Teutsch SM. How can economics advance prevention? Am J Prev Med. 2016;50(5 Suppl 1):S4-5.

14. Mariño RJ, Khan AR, Morgan M. Systematic review of publications on economic evaluations of caries prevention programs. Caries Res. 2013;47: 265-72

15. Tricco AC, Lillie E, Zarin W, O'Brien KK, Colquhoun H, Levac D, et al. PRISMA extension for scoping reviews (PRISMA-SCR): checklist and explanation. Ann Intern Med. 2018;169:467-73.

16. Gomersall JS, Jadotte YT, Xue Y, Lockwood S, Riddle D, Preda A. Conducting systematic reviews of economic evaluations. Int J Evid Based Healthc. 2015; 13:170-8.

17. Dos Santos WM, Aromataris E, Secoli SR, Matuoka JY. Cost-effectiveness of antimicrobial treatment for inpatients with carbapenem-resistant Klebsiella pneumoniae infection: a systematic review of economic evidence. JBI Database System Rev Implement Rep. 2019;17:2417-51.

18. Attwood D, Blinkhorn AS. Reassessment of the effect of fluoridation on cost of dental treatment among Scottish schoolchildren. Community Dent Oral Epidemiol. 1989;17:79-82.

19. Ehsani JP, Bailie R. Feasibility and costs of water fluoridation in remote Australian aboriginal communities. BMC Public Health. 2007;7:100. 
20. Frias AC, Narvai PC, De Araújo ME, Zilbovicius C, Ferreira Antunes JL. Cost of fluoridating the public water supply: a study case in the city of São Paulo, Brazil, 1985-2003. Cad Saúde Publica. 2006;22:1237-46.

21. Maupome G, Gullion CM, Peters D, Little SJ. A comparison of dental treatment utilization and costs by HMO members living in fluoridated and nonfluoridated areas. J Public Health Dent. 2007:67:224-33.

22. Ringelberg ML, Allen SJ, Brown LJ. Cost of fluoridation: 44 Florida communities. J Public Health Dent. 1992;52:75-80.

23. White BA, Antczak-Bouckoms AA, Weinstein MC. Issues in the economic evaluation of community water fluoridation. J Dent Educ. 1989;53:646-57.

24. Ko L, Thiessen KM. A critique of recent economic evaluations of community water fluoridation. Int J Occup Environ Health. 2015;21:91-120.

25. Alvesalo I, Reisine S, Hay J, Bailit HL. Effects of fluoride and regular dental care on personal dental expenditures of young adults in Finland. Community Dent Oral Epidemiol. 1982;10:15-22.

26. Garcia Al. Caries incidence and costs of prevention programs. J Public Health Dent. 1989;49:259-71.

27. Di Pasquale C. Various methods for community fluoridation--the situation in Africa. (a comparative study on cost benefits and cost effectiveness.). Odontostomatol Trop. 1983;6:7-18.

28. Di Pasquale C. Various methods of fluoridation in the community--situation in Africa. (comparative study of cost-benefits and cost effectiveness.) 2. Odontostomatol Trop. 1983;6:59-64.

29. Birch $\mathrm{S}$. The relative cost effectiveness of water fluoridation across communities: analysis of variations according to underlying caries levels. Community Dent Health. 1990;7:3-10.

30. Birch S. Measuring dental health: improvements on the DMF index. Community Dent Health. 1986;3:303-3011

31. Campain AC, Mariño RJ, Wright FA, Harrison D, Bailey DL, Morgan MV. The impact of changing dental needs on cost savings from fluoridation. Aust Dent J. 2010;55:37-44

32. Ciketic S, Hayatbakhsh MR, Doran CM. Drinking water fluoridation in south East Queensland: a cost-effectiveness evaluation. Health Promot J Austr. 2010;21:51-6

33. Cobiac LJ, Vos T. Cost-effectiveness of extending the coverage of water supply fluoridation for the prevention of dental caries in Australia. Community Dent Oral Epidemiol. 2012;40:369-76.

34. Davies GN. Fluoride in the prevention of dental caries. A tentative cost benefit analysis. Brit Dent J. 1973;135:131-4.

35. Doessel DP. Cost-benefit analysis of water fluoridation in Townsville, Australia. Community Dent Oral Epidemiol. 1985;13:19-22.

36. Griffin SO, Jones K, Tomar SL. An economic evaluation of community water fluoridation. J Public Health Dent. 2001;61:78-86.

37. Kroon J, van Wyk PJ. A model to determine the economic viability of water fluoridation. J Public Health Dent. 2012;72:327-33.

38. Manau C, Cuenca E, Martinez-Carretero J, Salleras L. Economic evaluation of community programs for the prevention of dental caries in Catalonia, Spain. Community Dent Oral Epidemiol. 1987;15:297-300.

39. Mariño R. Evaluación económica del programa de fluoración del agua de beber en Chile. Rev Chil Salud Pública. 2013;17:126-33.

40. Millan MT, Galvez AJ, Gomez E, Garcia A, Fernandez-Crehuet J. Cost-benefit analysis of fluoridating the public water supply of the city of Malaga. Gac Sanit. 1991;5(23):82-6.

41. Murgueytio P, Estupinan-Day S. Evaluación de costos y beneficios anticipados del Programa de Fluoruración del Agua Potable propuesto para la VIII Region, Chile. 1995. http://www1.paho.org/hq/dmdocuments/2009/ OH_CHI_EvalCostBenProgFluorAgua1995.pdf. Accessed 30 Aug 2019.

42. Nelson W, Swint JM. Cost-benefit analysis of fluoridation in Houston, Texas. J Public Health Dent. 1976:36:88-95.

43. O'Connell J, Rockell J, Ouellet J, Tomar SL, Maas W. Costs And Savings Associated With Community Water Fluoridation In The United States. Health Aff (Millwood). 2016;35:2224-32.

44. O'Connell JM, Brunson D, Anselmo T, Sullivan PW. Costs and savings associated with community water fluoridation programs in Colorado. Prev Chronic Dis. 2005:2:A06.

45. Tchouaket E, Brousselle A, Fansi A, Dionne PA, Bertrand E, Fortin C. The economic value of Quebec's water fluoridation program. Z Gesundh Wiss. 2013;21:523-33

46. Wright JC, Bates MN, Cutress T, Lee M. The cost-effectiveness of fluoridating water supplies in New Zealand. Aust N Z J Public Health. 2001;25:170-8.
47. Fyfe C, Borman B, Scott G, Birks S. A cost effectiveness analysis of community water fluoridation in New Zealand. N Z Med J. 2015:128:38-46.

48. Moore D, Poynton M, Broadbent JM, Thomson WM. The costs and benefits of water fluoridation in NZ. BMC Oral Health. 2017:17:134.

49. Carr S, Dooland M, Roder D. Fluoridation II: An interim economic analysis. Aust Dent J. 1980;25:343-8.

50. Arjunan KC. Economic Evaluation of Fluoridation of Water Supply to Prevent Dental Caries in Remote Communities in Australia: A Public Health Investment Analysis. 2000. https://ssrn.com/abstract=2975910. Accessed 30 Aug 2019.

51. Edelstein BL, Hirsch G, Frosh M, Kumar J. Reducing early childhood caries in a Medicaid population: a systems model analysis. J Am Dent Assoc. 2015; 146:224-32.

52. Atkins CY, Thomas TK, Lenaker D, Day GM, Hennessy TW, Meltzer MI. Costeffectiveness of preventing dental caries and full mouth dental reconstructions among Alaska native children in the Yukon-Kuskokwim delta region of Alaska. J Public Health Dent. 2016;76:228-40.

53. Kroon J, Van Wyk PJ. A retrospective view on the viability of water fluoridation in South Africa to prevent dental caries. Community Dent Oral Epidemiol. 2012;40:441-50.

54. Mariño R, Fajardo J, Morgan M. Cost-effectiveness models for dental caries prevention programmes among Chilean schoolchildren. Community Dent Health. 2012;29:302-8.

55. Barton P, Bryan S, Robinson S. Modelling in the economic evaluation of health care: selecting the appropriate approach. J Health Serv Res Policy. 2004;9:110-8.

56. Donaldson L, Bedi R. What are the chief medical officer's views on water fluoridation?. 2003 http://www.sirgeorgeyoung.org.uk/faq/newsitem. cfm?newsid=1545. Accessed 20 Feb 2020

57. Di Giovanni T, Eliades T, Papageorgiou SN. Interventions for dental fluorosis: a systematic review. J Esthet Restor Dent. 2018;30:502-8.

58. Brazier JE, Ratcliffe J, Tsuchiya A, Saloman J. Measuring and valuing health benefits for economic evaluation. 2th ed. United Kingdom: Oxford University Press; 2016.

59. Hettiarachchi RM, Kularatna S, Byrnes J, Scuffham PA. Pediatric quality of life instruments in Oral Health Research: a systematic review. Value Health. 2019;22:129-35.

60. Jakubiak-Lasocka J, Jakubczyk M. Cost-effectiveness versus cost-utility analyses: what are the motives behind using each and how do their results differ?- a polish example. Value Health Reg Issues. 2014;4:66-74.

61. Murray CJ, Evans DB, Acharya A, Baltussen RM. Development of WHO guidelines on generalized cost-effectiveness analysis. Health Econ. 2000;9: 235-51.

62. Laupacis A, Feeny D, Detsky AS, Tugwell PX. How attractive does a new technology have to be to warrant adoption and utilization? Tentative guidelines for using clinical and economic evaluations. CMAJ. 1992;146:47381.

63. Hutubessy RC, Baltussen RM, Torres-Edejer TT, Evans DB. Generalised costeffectiveness analysis: an aid to decision making in health. Appl Health Econ Health Policy. 2002;1:89-95.

64. Yothasamut J, Tantivess S, Teerawattananon Y. Using economic evaluation in policy decision-making in Asian countries: mission impossible or mission probable? Value Health. 2009;12(Suppl 3):S26-30.

65. Drummond M, Barbieri M, Cook J, Glick HA, Lis J, Malik F, et al. Transferability of economic evaluations across jurisdictions: ISPOR good research practices task force report. Value Health. 2009;12:409-18.

66. Ladewig NM, Camargo LB, Tedesco TK, Floriano I, Gimenez T, Imparato JCP, et al. Management of dental caries among children: a look at the costeffectiveness. Expert Rev Pharmacoecon Outcomes Res. 2018:18:127-34.

67. Ministerio de Salud de Chile. Revisión de la Literatura sobre la inclusión del criterio de costo-efectividad en guías de práctica clínica. 2013 http://www. repositoriodigital.minsal.cl/bitstream/handle/2015/775/3831.pdf?sequence= 1 \&isAllowed=y. Accessed 30 Aug 2019.

\section{Publisher's Note}

Springer Nature remains neutral with regard to jurisdictional claims in published maps and institutional affiliations. 